\title{
PERSPECTIVAS PARA O ENSINO CATÓLICO NO BRASIL ${ }^{1}$
}

\section{Perspectives pour l'Enseignement Catholique au Brésil}

Manoel Alves ${ }^{2}$

\section{Resumo}

A presente análise pretende, de forma perspectiva, traçar alguns indicativos da evolução futura do ensino católico no Brasil a partir da observação da sua atual estrutura organizacional e dos dados estatísticos do seu desempenho institucional na última década. A análise suscita questões importantes para o debate presente sobre o ensino católico no país frente às tendências em educação, adotando como eixo o modelo de gestão e as relações internas do ensino católico com as suas entidades mantenedoras e com as diversas instâncias da Igreja Católica, bem como as suas relações externas com o mercado educacional, a opinião pública e o Estado.

Palavras-Chave: Ensino católico; Ensino confessional; Gestão escolar; Mercado educacional; Tendências em educação; Sistema de ensino.

\section{Résumé}

La présente analyse prétend d'une façon perspective, élaborer quelques indicatifs de l'évolution future de l'enseignement catholique au Brésil á partir de l'observation de son actuel structure organisationnel et des données statistiques de son développement institutionnel au long de la dernière décade. Cet analyse suscite importantes questions pour le débat présent à propos de l'enseignement catholique au Brésil face aux tendances en éducation, en adoptant comme l'axe de l'analyse le modèle de gestion et les rapports internes entre l'enseignement catholique et ses organismes de tutelle et d'autres instances de l'Eglise Catholique, aussi bien que ses rapports externes envers le marché éducationnel, l'opinion publique et l'Etat.

Mots-Clés: Enseignement catholique; Enseignement confessionel ; Gestion scolaire; Marché éducationnel; Tendances en éducation.

1 Artigo baseado na conferência pronunciada no Seminário da ANAMEC - Associação Nacional de Mantenedoras de Escolas e Universidades Católicas do Brasil, em Brasília - DF, a 19 de outubro de 2005.

2 Doutor em Ciências da Educação pela Universidade de Paris VIII. MBA em Gestão de Negócios pela UFRJ. Professor Adjunto no Programa de Mestrado em Educação da Universidade Católica de Brasília. Especialista em Educação Confessional e em Gestão de Instituições de Ensino. malves@pos.ucb.br 


\section{Introdução}

Ao tratar das perspectivas do ensino católico no Brasil e lançar um olhar sobre o seu futuro, creio ser oportuno assinalar de início: 1. que tal futuro será, em grade parte, o que os responsáveis pelo ensino católico fizerem do seu presente, isso porque sonhos se constroem, aspirações se planejam e frutos se semeiam; 2. que não se pode generalizar a análise para a escola confessional como um todo de confessional ao se tratar da escola católica, considerando que, em que pesem as similaridades do contexto jurídico e de mercado entre as escolas confessionais de distintas denominações, constata-se que enquanto escolas de outros credos são fundadas, crescem e se expandem, a escola católica é campeã em retração, o que significa que a escola confessional no Brasil não tem uma trajetória homogênea.

Na minha rápida análise me atenho a três questões que creio serem nucleares na abordagem do tema, por entender que o futuro do ensino católico, qualquer que venha a ser, passa necessariamente por uma das seguintes questões:

1. A Gestão das Instituições Católicas de Ensino

2. O Sistema Católico de Ensino

3. As Relações do Ensino Católico com o Estado Brasileiro

Ao abordá-las, nesta ordem, optei por partir do particular para o geral. O objetivo da minha análise não é outro senão o de contribuir com a reflexão e o de provocar o debate sobre o tema. Afinal, não há como falar do futuro a não ser intuindo-o a partir da análise do presente. Estas três questões e os seus desdobramentos, a partir das quais introduzirei tal análise, são fruto de uma escolha pessoal em meio a tantas outras questões relevantes, talvez até mais importantes. Fiz, portanto, uma opção que certamente reflete o meu olhar, a minha percepção e a minha experiência sobre a realidade do ensino católico no Brasil de hoje, privilegiando as questões que julgo terão cada vez maior impacto na sobrevivência presente e futura do ensino católico. Cabe ainda precisar que minha análise sobre ensino católico se limita à educação básica, abstraindo-me de adentrar aspectos próprios do ensino superior. Isto não quer dizer que aspectos aqui assinalados não sem manifestem e não tenho impacto igualmente nas instituições de ensino superior católico. 


\section{Gestão das Instituições de Ensino Católicas}

\subsection{Estrutura Organizacional e Modelo de Gestão frente ao Cenário Educacional}

O cenário em que se encontra o ensino católico, hoje, no Brasil não é o da redução de concorrência, da diminuição do número de outras escolas privadas, do aumento da taxa de natalidade, da deteriorização da escola pública, do fim das ações antiéticas nas relações comerciais no seio do mercado educacional, da queda dos custos da educação, da melhoria na distribuição de renda, do aumento do poder aquisitivo da classe média, de uma menor intervenção estatal, de uniformidade cultural e religiosa na sociedade, de unanimidade na própria Igreja quanto ao papel e ao sentido do ensino confessional, da simplificação das exigências legais etc. Sem dúvida este é o cenário que agradaria muitíssimo aos dirigentes do ensino católico no Brasil, mas lamento informar que ele não existe! Este não é o mundo real onde se exerce a ação dos dirigentes e dos gestores do ensino católico. Consumir energia aspirando e atuando por este mundo irreal e fortemente improvável é postura quixotesca e irresponsável.

O grande desafio que se apresenta na atualidade na capacidade dos responsáveis pelo ensino católico de rapidamente se adaptarem a este ambiente, por mais agressivo e inóspito ele possa ser. A forma e a velocidade com que forem capazes de se reagir, hoje, a este cenário, irão determinar em grande parte o destino do ensino católico. Na educação privada, como em qualquer outro setor da vida social e da atividade econômica, por mais dura que seja a realidade existente, com as suas regras por vezes nefastas e perversas, seus responsáveis devem ser hábeis e competentes.

Parece ter chegado a hora de lamentar ou recriminar a realidade existente e de clamar por uma outra que não virá; de projetar no ambiente externo as idiossincrasias institucionais que impedem o ensino católico de ser eficaz e competitivo. Instituições não adaptadas a este cenário, como são a grande maioria das instituições confessionais de ensino, caminharão céleres e inevitavelmente para o seu fim, como que em um processo de seleção natural da espécie, onde a escola católica já é séria candidata a ser incluída no rol daquelas ameaçadas de extinção.

Suas estruturas organizacionais e seus modelos de gestão tendem a ser anacrônicos e ineficazes, convivendo pacificamente com a incompetência e com o desperdício. A falta de coragem e/ou de condições de reação e de tomada de decisões em torno de dimensões por vezes muito sensíveis nas entidades católicas de ensino as impedem de serem proativas, dinâmicas, competentes, ágeis, leves, tecnicamente preparadas etc. Sempre é mais fácil buscar 
fora as razões do insucesso que o ensino católico vem colhendo nas últimas quatro décadas, claramente manifesto em taxas elevadas de nossa retração no mercado educacional privado brasileiro.

Uma projeção linear destas taxas aponta para uma drástica redução da sua presença institucional em breve lapso de tempo. A última pesquisa do CERIS $^{3}$ (2005) demonstra inequivocamente tal retração, confirmando uma tendência assinalada pelas anteriores pesquisas CERIS (1996 e 1999). O fato é que o número de estabelecimentos de ensino católicos encerrando as suas atividades é cada vez maior em intervalos cada vez menores.

A realidade é inexorável para o ensino católico por meio de instituições privadas, nos moldes em que existe atualmente, que só tem possibilidades de prosperar se o negócio educacional pelo qual ele responde for eficazmente gerido. Buscar no ambiente externo e no mercado as razões do seu insucesso institucional e em possíveis formas de financiamento público a solução para o futuro do serviço educacional do ensino católico é deslocar o eixo da reflexão do ponto que se me apresenta como fulcral na presente análise e que irá garantir a viabilidade futura das entidades católicas de ensino: a eficácia da sua gestão. Ainda que o ensino católico contasse com um mercado educacional paradisíaco e com fartos recursos públicos em seus caixas, a persistir nas atuais estruturas de suas organizações e nos modelos de gestão que hoje predominam em suas instituições, os seus desafios não estariam em sua maior parte superados nem seus problemas resolvidos ou sua sobrevivência garantida.

\subsection{A Crise da Vida Religiosa e o Futuro do Ensino Católico}

Outro ponto que necessita de profunda reflexão, e que já é matéria vencida em outros países do mundo, é a estreita e nem sempre profícua relação entre a Vida Religiosa - VR (Ordens e Congregações Religiosas) e a o ensino católico. É difícil desassociar o futuro do ensino católico do atual contexto de crise pela qual passam as Ordens e Congregações Religiosas, especialmente aquelas dedicadas ao ensino. Falo aqui de crise de identidade, de estruturas, de conteúdos, de opções apostólicas, de redimensionamento de obras e de presenças, de projeto vocacional e eclesial. Existe, na minha percepção, um excessivo atrelamento entre a dinâmica de governo, o processo decisório e a estrutura institucional das Congregações Religiosas mantenedoras e a gestão dos estabelecimentos católicos de ensino.

Pesquisa realizada pelo CERIS - Centro Religioso de Investigação Social sobre a evolução estatística da Escola Católica no Brasil, com resultados divulgados em outubro de 2005. A mesma pesquisa foi realizada em 1996 e 1999. 
As realidades neste aspecto não são monolíticas, variando desde situações de abandono de algumas instituições de ensino por parte de seus responsáveis legais até intervenções inadequadas deles, passando por personalismos crônicos e freqüente instabilidade na condução das entidades, tanto das Mantenedoras quanto das próprias instituições de ensino. Tal atrelamento impede, via de regra, que o ensino católico atinja os níveis de profissionalização mínimos na gestão para torná-lo competitivo e suficientemente rápido e capaz em responder aos desafios novos e crescentes do mercado educacional. As grandes Instituições de Ensino Superior (IES), seja pelo seu lastro institucional seja pelas competências técnica e teórica nelas alocadas, seguirão, ainda que por movimento inercial, a sua trajetória. Já não se pode assegurar o mesmo para as pequenas e novas IES católicas, provavelmente sujeitas ao mesmo futuro dos estabelecimentos de ensinos fundamental e médio.

Como falar do futuro do ensino católico se muitas das Congregações Religiosas mantenedoras não têm segurança do que pretendem em relação aos seus estabelecimentos de ensino no presente. O futuro e a sobrevivência do ensino católico não é desafio de uma única Mantenedora em particular ou de todas separadamente. Aliás, em perspectiva eclesial, nenhum estabelecimento católico de ensino pertence a esta ou àquela Congregação Religiosa mantenedora, sendo seu futuro responsabilidade de todos, mormente do episcopado.

\subsection{As Lideranças da Escola Católica - por onde andarão?}

No novo ciclo de organização social e econômica em que a Humanidade apenas adentra, conhecido sob o epíteto genérico de sociedade do conhecimento, acentua-se, no âmbito das organizações, o papel decisivo do líder. É inconteste em um contexto de aceleradas e profundas mudanças, em que decisões ágeis são exigidas a todo instante, que o valor agregado e a capacidade competitiva de uma instituição de ensino passam, necessariamente, pela capacidade do líder em mobilizar adequadamente o conjunto dos recursos de que ela dispõe. Exige-se, do líder, pois, uma plêiade de competências intelectuais, gerenciais e relacionais cada vez maiores, as quais devem ser continuadamente adquiridas e/ou desenvolvidas.

No ensino católico constata-se uma crescente lacuna nas lideranças. Os seus dirigentes, na sua maioria, se constituíram a frente das instituições em que atuam por vezes há muitas décadas e a renovação de quadros é restrita. Há uma tendência de perpetuação de pessoas em cargos e fun- 
ções. Nem sempre tais pessoas revelam adaptação em responder às novas demandas das instituições de ensino. Por parte das novas gerações de dirigentes das escolas católicas e de suas entidades mantenedoras constatamse graves lacunas em competências, habilidades e posturas, tanto humanas quanto profissionais, referindo-me, particularmente, aos religiosos, membros destas Congregações.

No que concerne à atuação do laicato do ensino católico, o quadro não é mais animador. Fundamentalmente o que ocorre é que ainda não se conseguiu recuperar no âmbito do ensino católico o papel do laicato em animar as realidades técnicas e profissionais, como desde há muito aponta a Exortação Apostólica de Paulo VI Evangelii Nuntiandi (1975). De um lado predomina o olhar de suspeição para com os leigos; de outro lado o ensino católico carece de consistentes programas de formação e acompanhamento dos leigos, mormente dos dirigentes. Carece, igualmente, de estruturas e processos de gestão adequados ao acompanhamento de sua atuação em todos os níveis, com ênfase nos financeiros e patrimoniais. Carece, ainda e uma vez mais, de uma competitiva gestão de pessoas, voltada para o recrutamento, seleção e retenção dos profissionais; o que costuma desembocar no lânguido lamento quando um dos seus colaboradores se esvai para as fileiras do concorrente, deixando um sentimento de traição.

No concernente às lideranças do ensino católico a crise da Vida Religiosa anteriormente abordada também se reflete. Desta feita, não há como fugir da evidência do forte impacto sobre as relações do ensino católico com o mercado educacional exercido pela baixa qualidade dos seus quadros, especialmente de suas lideranças, quando comparados com os profissionais e dirigentes dos gestores e líderes das demais instituições privadas concorrentes. A questão das lideranças e da formação de quadros não se limita aos aspectos gerenciais, materiais e financeiros, mas transpira igualmente, quanto às suas lacunas, nos espaços acadêmico e mesmo religioso, com reflexo inevitável na qualidade do serviço educacional e na manifestação da identidade confessional do ensino católico.

Concluindo este ponto assinalo que as pessoas são o principal ativo de uma instituição de ensino e que por esta razão deveriam ser prioridade nas políticas gerenciais delas. Não há como vislumbrar futuro promissor para o ensino católico no Brasil sem uma completa renovação das suas lideranças e dos seus quadros, religiosos ou leigos, tanto diretivos quanto técnicos e docentes, mediante a urgente implementação de uma nova política em gestão de pessoas. 


\section{Sistema Católico de Ensino ${ }^{4}$}

A primeira e dura constatação é que não existe no Brasil, ao contrário de inúmeros outros países, um Sistema Católico de Ensino. Este conceito freqüentemente utilizado por muitos de nós é em geral vazio de sentido. A força ao qual tal Sistema pretenderia se perde na semântica. Mesmo no nível conceitual é refém de uma ampla polissemia. Ninguém consegue definir em que realmente tal Sistema consiste ou em que eventualmente ele consistiria. Os níveis de relacionamento e operação sistêmica entre as possíveis unidades deste sistema (Instituições de Ensino Básico e Superior, Entidades Mantenedoras e Organismos Nacionais de Educação Católica ${ }^{5}$ ) são inexistentes ou muito frágeis, quando não plenos de desconfianças, de ranços históricos e de vieses competitivos, ainda que possa parecer surrealista.

Não se pode nem sequer falar em ameaça ao Sistema Católico de Ensino, porque tal Sistema não é real, não existindo para ser ameaçado. A idéia do Sistema prende-se a uma nefasta virtualidade que pode induzir ao equívoco do ensino católico se julgar organizado, forte, estruturado, enquanto o que realmente graça entre suas instituições e seus dirigentes é o individualismo e a desarticulação.

Da criação dos diversos organismos nacionais de educação católica até hoje podem se constatar inúmeras ações de extrema relevância desenvolvidas em prol das instituições católicas de ensino, mas pouquíssimo se avançou organicamente. De um lado faltou maior agressividade dos Organismos, e de outro lado sobraram resistências das instituições de ensino católico a projetos novos e inovadores, de maior envergadura, ainda que implicassem em redirecionar os próprios investimentos e em abrir mão de certo grau da sua autonomia. Ainda predomina entre no seio do ensino católico no Brasil o cada um por si e Deus por todos!

Precisando melhor este tema do Sistema de Ensino Católico, para existir de fato, ele deve se caracterizar por:

1. um ensino católico no Brasil avance na direção de um todo forte e articulado, onde o meu e o teu cedem lugar ao nosso;

\footnotetext{
Este foi o tema de meu artigo publicado neste periódico na sua edição de setembro/dezembro de 2005. Assim sendo, sem retornar com maior profundidade o mesmo tema, remeto o leitor ao referido artigo. Aqui pretendo apenas precisar com o aporte que se seguirá o que caracterizaria tal Sistema de Ensino Católico.

5 São Organismos Nacionais de Educação Católica: a Associação de Educação Católica - AEC do Brasil, fundada em 1945; a Associação Brasileira de Ensino Superior Católico - ABESC, fundada em 1954; a Associação Nacional de Mantenedoras de Escolas Católicas - ANAMEC, fundada em 1993.
} 
2. um ensino católico que deixe de ter suas instituições percebidas umas pelas outras como concorrentes, e, em alguns casos, até o maior e o mais temido deles;

3. instituições de ensino que se preocupem com as outras suas congêneres e, por isso, não aceitam passivamente quando uma escola católica anuncia que está fechando as suas portas (muito menos vibra na estratégia de absorver seus alunos remanescentes);

4. um episcopado que assuma a sua responsabilidade pastoral pelo presente e pelo futuro do ensino católico, e o constitua em efetiva prioridade pastoral;

5. um único Organismo Nacional de Ensino Católico quando o passado for abandonado para, corajosamente, se superar a atual situação em que três entidades nacionais (AEC, ABESC e ANAMEC), completamente autônomas, conduzem projetos e políticas, por vezes até antagônicas quanto aos seus princípios e às suas ações, em flagrante desperdício de energia e de recursos;

6. estruturas permanentes, eficazes, e de baixo custo forem capazes de oferecer aos estabelecimentos de ensino católico e às suas entidades Mantenedoras serviços diversos e dos quais eles realmente necessitam, retirandoos da exposição em que se encontram frente a incompetentes e a aproveitadores;

7. serviços e iniciativas, inovadoras e de alto valor agregado, construídas coletivamente, de forma participativa, criando elevada sinergia interinstitucional e permitindo que todos juntos suportem os custos elevados em que as novas tecnologias educacionais implicam;

8. projetos concretos que revelem e fortaleçam espaços e importantes iniciativas no âmbito, por exemplo, da científica avaliação acadêmica e institucional, da eficaz gestão dos ativos financeiros, da adequada orientação jurídica e da prática dos dispositivos legais, do efetivo fortalecimento da imagem institucional, de amplo desenvolvimento de tecnologia educacional e de funcional etc;

9. políticas e decisões relativas ao ensino católico no Brasil conduzidas pelas entidades, às quais estão vinculadas um sem número de ações socioassistenciais, e não pelas prioridades e interesses das instituições de ensino superior, elas por si mesmas muito mais fortes e organizadas.

O ensino católico no Brasil se encontra, hoje, diante de um quadro triste de frágil articulação e de ausência de significativas estruturas de apoio às suas instituições. Diante deste quadro como se pode falar em Sistema Católico de Ensino!?. Caso se opte decididamente por edificar tal Sistema muitos destas características apontadas devem se implementar previamente. 


\section{Relações da Escola Católica com o Estado Brasileiro}

As relações entre Educação e Estado no Brasil vêm sofrendo mudanças significativas nas últimas duas décadas. O ensino católico sofre particularmente as conseqüências em virtude de sua natureza filantrópica. A cada dia as entidades Mantenedoras de estabelecimentos de ensino católico se vêem empurradas para um cipoal legal em que se tem a impressão de estarem vivendo uma completa subversão da ordem jurídica estabelecida, por vezes tendo que conviver com verdadeiras arbitrariedades. Corro o risco de lançar aqui algum ponto do debate de forma superficial. Faço-o por considerar que as relações entre Estado e ensino católico não se reduzem a aspectos jurídicos, mas ombreando-os encontram-se aspectos organizacionais, políticos e identitários não menos importantes nesta análise. Análise que não pode, igualmente, ser desenvolver fora da reflexão sobre o Sistema Católico de Ensino na forma em que o abordei anteriormente.

As relações da Escola Católica com o Estado brasileiro circunscrevemse em aspectos da nossa História que se cristalizaram em: 1. posições ideológicas de setores diversos da Sociedade (mormente da intelectualidade e da academia); 2. posturas corporativistas (especialmente das entidades de classe dos docentes e dos sindicatos patronais); 3. percepções plurais e seguidamente inamistosas por parte da opinião pública (incluindo aí seus ex-alunos, suas comunidades educativas e, até mesmo, mirabile dictu, setores da própria Igreja).

As relações do ensino católico com o Estado brasileiro não poderão se dar fora do âmbito destes aspectos apontados. Haverá naturalmente uma concomitância no debate sobre a liberdade de ensino e o direito ao financiamento público para o ensino católico, se constituindo, de certa forma, em um só e mesmo debate, como que duas faces da mesma moeda e, por isso, os argumentos e as opções institucionais devem estar bem articulados. Este debate deve considerar sempre duas dimensões de elevada complexidade: 1 . onde termina a responsabilidade do Estado e começa o seu intervencionismo na livre iniciativa na educação e 2 . em que consiste a liberdade de ensino e a quem cabe arcar com tal liberdade (autonomia) e até que nível. Estas são duas dimensões recorrentes em qualquer debate sobre a relação entre escola confessional e Estado.

Assiste-se no momento presente do país a um acentuado processo de intervenção do Estado na livre iniciativa em educação, extrapolando em muito as suas atribuições constitucionais considerando o que reza o artigo 209 da Constituição Federal de 1988: O ensino é livre à iniciativa privada, atendidas as seguintes condições: cumprimento das normas gerais da educação nacional; autorização e avaliação de qualidade pelo poder público. Intervenção que se aproxima de certa dose de autoritarismo e que desrespeita legislação já 
consolidada e aplicável ao setor da educação privada. Seguidamente o setor tem sido surpreendido por tal processo e nem sempre reagido adequadamente. Causa espécie postulados do PROUNI, da Reforma Universitária, dos Exames Nacionais (SAEB e ENEM), da ampliação de conteúdos curriculares e dos anos de escolaridade do ensino fundamental etc., sem mencionar as ações relativas à identidade filantrópica das entidades de beneficência e assistência social que atuam no ensino formal e seriado, como é o caso da maioria das Mantenedoras de escolas católicas no Brasil.

Enquanto isso o ensino católico segue defendendo o princípio de que suas instituições são, por essência, instituições de natureza pública, embora de direito privado. Tal princípio, que entendo legítimo, evocaria para o ensino católico o direito de ser considerado e tratado de forma diferenciada das demais escolas privadas, no que concerne seu financiamento, já o sendo quanto à sua carga tributária. Tal distinção, relativa a este mesmo princípio, está expressa na atual Carta Magna (artigo 213). Não posso deixar, no entanto, de apontar para uma possível incongruência (ou paradoxo) que emerge seguidamente do discurso da Escola Católica com base em tal princípio quando se recusa a fugir do ônus da prestação de contas e da dependência na decisão sobre a aplicação os recursos próprios de quem se serve de recursos públicos para seu funcionamento.

Desejar diferenciação pressupõe oferecer contrapartidas que irão certamente na direção de uma maior intervenção do Estado, mormente na sua gestão acadêmica e financeira, a exemplo do que ocorre em outros países. É necessário ter consciência que conquistar certos direitos (ou distinções) tem um preço. Este preço costuma ser pago com a autonomia. Neste debate não se pode esquecer igualmente a confusão a que se prestaria uma possível dissonância entre o princípio da defesa do legítimo direito à livre iniciativa na educação (o direito da escola particular de operar livremente) e o discurso de reserva de mercado, que busca fugir da livre concorrência, do qual o ensino católico poderia ser acusado por outros segmentos do ensino privado do país.

A opção do ensino católico neste tocante tem de ser clara, responsável e coerente. Ainda que não sejam posições antagônicas, inconciliáveis e excludentes, é preciso optar por uma delas: ou repúdio a qualquer intervenção estatal na livre iniciativa em educação ou a luta pela participação estatal direta no financiamento da escola confessional. Buscarei agora sintetizar, sob forma de etapas a serem percorridas, as possíveis posições do ensino católico para avançar nas suas relações com o Estado brasileiro na perspectiva da sua salvaguarda institucional futura. Tais etapas pressupõem uma nova aprendizagem institucional do nosso ensino católico a exemplo de outros países em que as conquistas no tocante à liberdade de ensino e ao financiamento estatal para a escola confessional foram longas, penosas e exigiram muita organização 
prévia, o que ainda está longe de ser a realidade no Brasil no ensino católico e no ensino confessional de modo geral.

1. ${ }^{\text {a }}$ etapa - Constituir o Sistema Católico de Ensino deve ser a primeira e grande opção do ensino católico neste momento histórico da sua trajetória no país;

2. ${ }^{\text {a }}$ etapa - Defender a liberdade de ensino plena e sem reservas, em um mercado livre e sem controles estatais, com completa autonomia financeira e gerencial (o combate à intervenção estatal será sempre ponto importante a ser defendido pelo Sistema Católico de Ensino em que pesem outras opções de sua parte);

3. ${ }^{\text {a }}$ etapa - Organizar a luta por financiamento público a partir de uma estrutura forte e central do Sistema Católico de Ensino, atuando prioritariamente em nível municipal, encetando profícua parceria público-privada para a universalização do acesso à educação de qualidade.

Antes de o ensino católico decidir se lançar em tal empreitada é importante ter ciência de que em nenhuma parte do mundo tais conquistas foram fáceis e irreversíveis. Vale assinalar a existência de restrições e dificuldades que ainda perduram nos países que já conquistaram subvenções públicas do Estado; apesar do fato de terem conquistado tais direitos em contexto social e econômico muito mais favorável do que o do presente momento da história brasileira. Ainda assim ocorrem nestes países, seguidamente, retrocessos em alguns destes direitos já conquistados, implicando em graves transtornos para as instituições confessionais de ensino que, tendo se estruturado para subsistir com recursos públicos, se vêem de uma hora para a outra sem condições de financiamento e com serí́ssimas dificuldades em se manterem.

A Escola Católica no Brasil ao lançar tal debate não estaria querendo caminhar na contra mão da história!? Vale igualmente recordar que nos países onde esta posição foi vitoriosa exigiu que a opinião pública fosse às ruas em defesa da escola confessional e que o episcopado local assumisse a liderança de tal processo. Sem tais precondições asseguradas e sem um concreto e eficaz Sistema Católico de Ensino pode ser temerário para o ensino católico no Brasil abraçar pública e politicamente esta posição. Nesta perspectiva, e enquanto estas questões e seus inúmeros desdobramentos não forem corajosamente debatidos internamente, é oportuno igualmente perguntar-se se lançar um debate nacional pela efetivação do direito à subvenção pública para a escola confessional se constitui em prioridade neste momento histórico do país e do ensino católico. De toda feita não me parece uma possibilidade real que uma posição desta natureza se sustente enquanto o Sistema Católico de Ensino for apenas uma idéia, uma virtualidade de alguns. 


\section{À guisa de conclusão... um olhar para o futuro.}

O futuro do ensino católico no Brasil... quem pode prevê-lo? Pensar no futuro do ensino católico não é nada além do que um exercício de prolongar no tempo o que se percebe em potência e se constata pela análise de fatos e estatísticas da realidade presente da evolução dos estabelecimentos católicos de ensino em confronto com as emergentes tendências em educação e ensino no país e no mundo. Tais tendências se asseveram particularmente impactantes em algumas dimensões que em breve alcançarão igualmente o ensino católico. Diversos estudos apontam tendências futuras para o ensino as quais parecem estar ligadas mundialmente a três palavras-chave: relevância, qualidade e internacionalização; conceitos que passarão a ser o foco principal das instituições de ensino nos próximos anos.

Entre tais tendências selecionei as seguintes, a partir das quais o ensino católico deve estar pensando o seu futuro: redução na margem de lucro das instituições de ensino; crescimento da educação executiva; profissionalização da gestão nas instituições de ensino; aumento da diferenciação do sistema (tipos de escolas e serviços que elas oferecem); concorrência aluno a aluno; concorrência por funcionário e professores; deselitização do ensino superior; especialização das instituições de ensino; crescimento do ensino focado nas necessidades das corporações e dos indivíduos; diversificação e flexibilização na oferta de cursos e serviços educacionais; desterritorialização da concorrência; presença do capital estrangeiro; crescimento no número de alunos "não-tradicionais" como consumidores da educação; flexibilização dos cursos e serviços prestados; personalização e flexibilização dos currículos; revisão do papel e da função social da educação; aumento da educação corporativa; presença maciça da tecnologia na educação; aumento do ensino a distância; aumento do número de ações e processos contra as instituições de ensino nos órgãos de defesa do consumidor, entre outras.

Devo ser bastante sincero na minha percepção quanto ao futuro do ensino católico, a partir da sua realidade presente, quando confrontado com as suas atuais condições estruturais e institucionais a as tendências acima apontadas: não vejo razões para otimismo. A menos que os dirigentes e responsáveis pelo ensino católico no Brasil tenham a coragem de promover, juntos, uma grande revolução, a partir de um Sistema Católico de Ensino efetivo e operacional, liderados por um único organismo nacional de Educação Católica, suficientemente forte, articulado e articulador, expressão dos anseios e garantidor das suas necessidades, o seu horizonte não é promissor.

Cabe perguntar até quando os dirigentes e os responsáveis pelo ensino católico no Brasil vão permitir que tudo prossiga como está? Quanto do aqui analisado tem sido por eles efetivamente considerado? Diante disso poder-se-ia concluir com duas verdades das quais não se pode fugir e que ficam aqui como 
alerta: primeiro que a única realidade permanente no Universo é a mudança, como dizia Heráclito; segundo que o futuro do ensino católico no Brasil depende exclusivamente das atuais opções de suas lideranças.

\section{Referências}

ALVES, Manoel. A Vida religiosa e a educação das elites no atual contexto brasileiro.alguns conflitos e contradições inerentes à educação das elites brasileira pela Igreja dos pobres. In: PAIVA, Vanilda (Org.). Catolicismo, educação e ciência. São Paulo, SP: Loyola, 1991. p. 358.

El religioso educador face à lãs grandes tendências y retos de L'educación católica en América Latina rumbo al siglo XXI. Testimonio, Santiago de Chile, n.152 p. 4-20, nov./dez. 1995.

. O papel das mantenedoras nas organizações da educação católica no Brasil.In: SEMINÁRIO DA ASSOCIAÇÃO NACIONAL DE MANTENEDORES DE ESCOLAS CATÓLICAS, Brasília, DF. 1996. Anais. Brasília, ANAMEC, ago. 1996. p. 265

Sistema católico de educação e ensino no Brasil: uma nova perspectiva organizacional e de gestão. Revista Diálogo Educacional, Curitiba, v. 5, n.16, p. 209-228, set./dez. 2005.

Le rôle de l'école catholique dans la formation des elites au Brésil 1962-1992: métacritique d'un systéme complexe.Thèse (Doctorat ,SaintDenis) - Université de Paris VIII, 2000.p. 1200.

Sistema Católico de Educação e Ensino no Brasil: uma nova perspectiva organizacional e de gestão educacional. Revista Diálogo Educacional. Curitiba, v. 5, n. 16, p. 209-228, set./dez. 2005.

ARROCHELLAS, Maria Helena (Org.). Classes médias e a opção preferencial pelos pobres. São Paulo, SP: Paulinas, 1983. p. 131.

CASTELLS, Manuel. A Sociedade em rede: a era da informação: economia, sociedade e cultura. São Paulo, SP: Paz e Terra, 1999. v. 1. p. 617.

CERIS - Centro de Estatística Religiosa e Investigação Social e ANAMEC Associação Nacional de Mantenedoras de Escolas Católicas. Pesquisa sobre as escolas católicas do Brasil - 1996: levantamento dos estabelecimentos de ensino superior católico do Brasil - 1996. Brasília, DF: ANAMEC, 1997. p. 62.

CERIS - Centro de Estatística Religiosa e Investigação Social e ANAMEC-Associação Nacional de Mantenedoras de Escolas Católicas. Pesquisa sobre as obras sociais da Igreja Católica - atuação das escolas 1998: atualização das informações sobre as escolas católicas 1996 - 1999. Brasília, DF: ANAMEC, 2000. p. 61 
CERIS - Centro de Estatística Religiosa e Investigação Social e ANAMEC-Associação Nacional de Mantenedoras de Escolas Católicas. Censo das escolas católicas no Brasil. Relatório. Brasília, DF: CERIS: ANAMEC, 2005. p. 73. (Mimeografado)

CONFERÊNCIA Nacional dos Bispos do Brasil. Para uma pastoral da educação. São Paulo, SP: Paulinas, 1986. p. 137.

Educação, igreja e sociedade. São Paulo, SP: Paulinas, 1992. p. 86.

CONCILE Oecumenique Vatican II. Constitution Dogmatique Lúmenm Gentium, 1964; Consitution Pastoral Guadium etSpes, 1965; Declaration Gravissimum

Educationis, 1965, Biblioteca de Autores Cristianos. 27. ed. Madrid: La Editorial Católica, 1975.

CONSTITUIÇÃO da República Federativa do Brasil.Brasília, DF: Senado Federal, 1988.

CRESPO, Samyra B. de Serpa. Progressismo católico, educação libertadora no Brasil: uma contribuição à história das ideologias. Rio de Janeiro, RJ: UFRJ. 1989. p. 391.

CUNHA, Rogério I. A. Teologia da libertação e pedagogia libertadora. Revista de Educação da AEC, Brasîlia, n. 67, p. 37-50, jan./mar. 1988.

CURY, Carlos R. Jamil. Ideologia e educação brasileira: católicos e liberais. 4. ed. São Paulo, SP: Cortez, 1988. p. 201.

GARCIA, Jacinta Turolo; CAPDEVILLE, Guy (Orgs.). Educação Católica. Bauru: EDUSC, 2001, p. 176.

GIUSTINA, Osvaldo Della. Rumos e desafios da escola católica. Boletim da AEC, Porto Alegre, n. 31, 1989.

JULIATTO, Clemente. A Universidadeem busca da excelência: um estudo sobre a qualidade da educação. Curitiba: Champagnat, 2005. p. 240.

MEYER JR, Victor e MURPHY, J. Patrick, organizadores. Dinossauros, gazelas \& tigres: novas abordagens da administração universitária. 2. ed. ampl. Florianópolis: Insular, 2003. p. 211.

PAIVA, José Maria. Colonização e catequese 1549-1600. São Paulo, SP: Cortez, 1982. p. 108.

Papa PAULO VI. Exortação apostólica Evangelii Nuntiandi. São Paulo, SP: Paulinas, 1975. 